\title{
Shield Reliability Analysis-Based Transfer Impedance Optimization Model for Double Shielded Cable of Electric Vehicle
}

\author{
Xiaoshan Wu $\mathbb{D},{ }^{1}$ Xiaohui Shi, ${ }^{2}$ Jin Jia $\mathbb{D}^{2},{ }^{2}$ Heming Zhao, ${ }^{3}$ and $\mathrm{Xu} \mathrm{Li}$ \\ ${ }^{1}$ School of Automotive Engineering, Chongqing University, Chongqing 401331, China \\ ${ }^{2}$ Vehicle Engineering Institute, Chongqing University of Technology, Chongqing 400054, China \\ ${ }^{3}$ Chongqing Qingyan Ligong Electronic Technology Co., Ltd., Chongqing 400020, China
}

Correspondence should be addressed to Jin Jia; jj@cqcii.com

Received 25 August 2020; Accepted 9 October 2020; Published 8 February 2021

Academic Editor: Yong Chen

Copyright (C) 2021 Xiaoshan Wu et al. This is an open access article distributed under the Creative Commons Attribution License, which permits unrestricted use, distribution, and reproduction in any medium, provided the original work is properly cited.

Due to the high-voltage and high-current operating characteristics of the electric drive system of electric vehicles, it forms strong electromagnetic interference during the working process. The shielding effectiveness of the high-voltage connection cable that connects the components of the electric drive system is directly related to its electromagnetic interference emissions. Therefore, the modeling and analysis of the shielding effectiveness of the connection cable is very important for the development of a connection cable with good shielding effectiveness. Firstly, the transfer impedance value representing the shielding effectiveness of the shielded cable is analyzed, and the difference between the single-layer shield and the double-layer shield cable is compared. The influence of double-layer shielded high-voltage connection cables commonly used in electric vehicles on the shielding layer DC resistance and keyhole inductance is clarified. Secondly, the transfer impedance optimization model $Z_{T \_D \text {-Desmoulins }}$ is obtained by combining with the single-layer shielded cable Desmoulins model and considering the influence of shielded layer DC resistance and keyhole inductance. Finally, three double-layer shielded cables of different types were selected for the triaxial test. The error rates of the test data and the $Z_{T_{-} D \text {-Desmoulin }}$ optimization model are all lower than $20 \%$ in each frequency band, which verified the correctness, universality, and great engineering application value of the optimization model.

\section{Introduction}

Due to the high-voltage and high-current working characteristics of the electric drive system of electric vehicles, strong electromagnetic interference is formed during the working process. The shielding effectiveness of the highvoltage connection cables that connect the components of the electric drive system is directly related to its electromagnetic interference emission level $[1,2]$. The connection cables with poor shielding efficiency usually cause the electromagnetic field emission level of the entire electric vehicle to exceed the standard. Therefore, how to effectively evaluate and test the shielding effectiveness of the connector assembly is the common concern for cable and connector suppliers and vehicle manufacturers.

To solve the above problems, scholars at home and abroad have carried out extensive research on the surface transfer impedance of the connection cables. Vance [3] deeply studied the low-frequency characteristics when radiating to the cable braid and gave the most commonly used $Z_{d}$ model formula. The braided inductance part was introduced by Tyni [4] to improve the accuracy when calculating the transfer impedance of high and low projection coverage cables; Demoulin and Degauque [5] proposed a new model that took into account the effects of additional fluctuations and generated additional attenuation; Marconi et al. [6] proposed a test method to measure the transfer impedance of two coaxial cables RG 213 under the same conditions and compared the test results with theoretical calculations; Xiaoling et al. [7] proposed a new model for accurately predicting the transfer impedance of braided coaxial cables by summarizing and studying the classical model; Mushtaq and Frei $[8,9]$ introduced the ground plate method (GPM) and capacitive voltage probe (CVP). He 
compared the test results of the above methods with the triaxial injection method and line injection method. The above studies all used braided single-layer shielded cables as the research object. At present, high-voltage power cables on electric vehicles usually use double-layer shielding. The socalled double-layer shielding refers to the inner shielding layer using tinned copper wire braiding. The outer shielding layer is wrapped with aluminum-plastic composite tape (aluminum foil). However, domestic and foreign experts have not conducted in-depth research on the modeling method of double-layer shielded cables. The transfer impedance model of double-layer shielded cables is of great significance to the shielding effectiveness of vehicles. Therefore, it is necessary to carry out the research of the surface transfer impedance of the double-layer shielded cable connection cables.

In view of the above analysis, this article first introduces the difference in transfer impedance between single- and double-shielded cables, and the influence of double-layer shielded high-voltage connection cables used in electric vehicles on the shielding layer DC resistance and keyhole inductance is clarified. Then, based on the Demoulin model, the equivalent circuit diagram of the double-layer shielded cable is obtained by considering the influence of the shield layer DC resistance and keyhole inductance, and the optimization model of the double-layer shielded cable is established. Three sets of double-shielded cables are tested by the tri-coaxial method, and the correctness and generality of the optimized model are verified.

\section{Surface Transfer Impedance and Its Analytical Formula}

2.1. Surface Transfer Impedance. Surface transfer impedance $[10,11]$ is a characteristic parameter that characterizes the shielding performance of power cables. The lower the transfer impedance, the better the shielding performance of the cable and the stronger its electromagnetic immunity. It is defined [12] as the unit length of the cable. The induced voltage formed between the core wire and the shield layer when current flows through the shield layer (as shown in Figure 1), that is, the ratio of the axial voltage change rate on the braid layer to the axial current, and the calculation formula can be expressed as follows:

$$
Z_{T}=\frac{1}{I_{0}} \frac{\partial V}{\partial z}
$$

where $I_{0}$ represents the current flowing through the outer surface of the braid; $(\partial V / \partial z)$ represents the effective value of the voltage per unit length of the uniform transmission line composed of the core wire and the shielding layer; $z$ indicates the axial direction of the cable, as shown in Figure 1; $l$ indicates the cable length.

2.2. Transfer Impedance Analytical Formula. Generally, the high-voltage power cables used in electric vehicles are braided shielded cables. As shown in Figure 2, the analytical model of the transfer impedance can be established by the

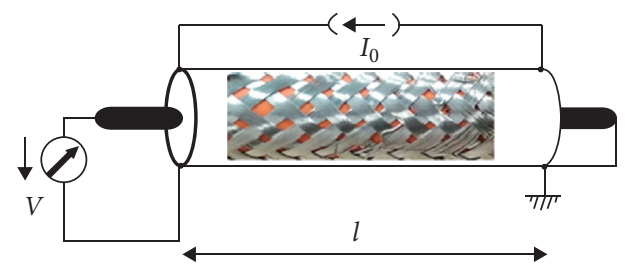

FIGURE 1: Schematic diagram of transfer impedance definition.

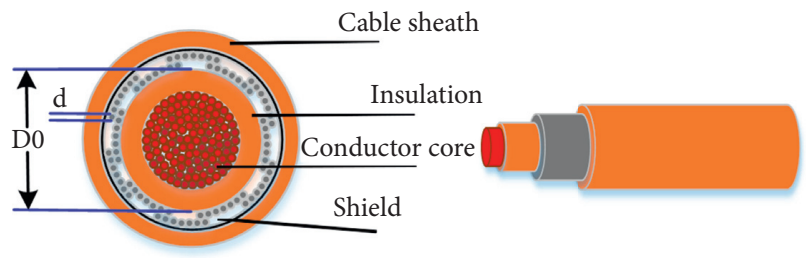

FIgURE 2: Schematic diagram of the shielded cable structure.

structural parameters of the cable braid and the electromagnetic field theory.

The analytical method can effectively analyze the influence of the parameterization of the shielded cable on the transfer impedance. Regarding the input parameters of the analytical model, the structural characteristics of the cable braid can be described by 7 parameters: the inner diameter of the braid $D_{0}$, the diameter of the braided wire $d$, the number of braid strands contained in a circle on the braided layer $c$, the number of wires in each braided bundle $N$, the braid angle $\alpha$, the conductivity of the braided layer $\sigma$, and the magnetic permeability of the braided layer. After these parameters, the transfer impedance value of the shielded cable can be simulated; refer to the schematic diagram in Figure 3.

\subsection{Analysis of Transfer Impedance Characteristic Curve.} For power shielded cables, the equivalent circuit can be built through the RLC electrical parameters, as shown in Figure 4. The inductance parameter $L$ is mainly composed of the inductance Lc of the core conductor, the inductance Ls of the shielding layer, and the mutual inductance M_cs between the two. In addition, the influence of small hole inductance and braided inductance Lh and Lb should be considered on the braided layer. The resistance parameter $R$ is mainly composed of the resistance of the internal conductor Rc and the resistance of the shielding layer Rs. The resistance is affected by the skin effect and changes with frequency. The skin effect will affect the shielding effectiveness of the cable and the impedance value at the resonance frequency. The capacitance parameter $\mathrm{C}$ is composed of the capacitance C_cs between the core wire and the shielding layer. The transfer impedance value is mainly affected by inductive coupling, so we should pay attention to the influence of these electrical parameters on the transfer impedance of the power cable [13].

As shown in Figure 5, the composition of the $Z_{T}$ curve of the shielded cable transfer impedance model is analyzed. The dotted lines in the figure are several key components that 


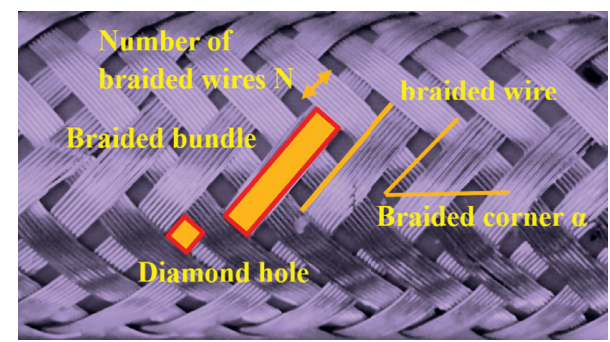

Figure 3: Schematic diagram of the structural parameters of the braid.

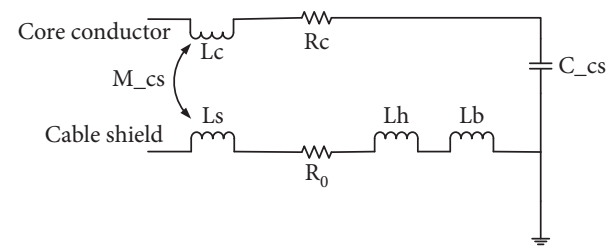

Figure 4: Shielded cable equivalent circuit diagram.

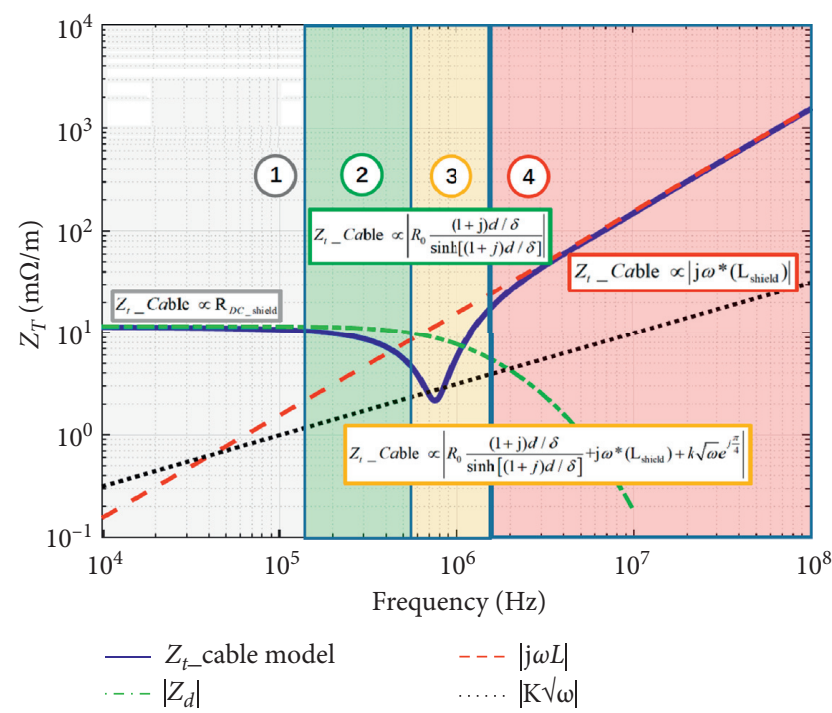

FIgURe 5: $Z_{T}$ curve composition analysis diagram.

affect the value of transfer impedance, where $Z_{d}$ is scattering impedance and $j \omega L$ is inductance and respectively, and the solid lines in the figure are the transfer impedance curves containing each component. In area 1 (gray), when the low frequency is less than $150 \mathrm{kHz}$, the current density in the braided shielding layer is evenly distributed, and the transfer impedance value is approximately the same as the DC resistance value $R$ of the shielding layer. In zone 2 (green), the transfer impedance is mainly determined by the scattering impedance $Z_{d}$. As the frequency increases, the current density in the shielding layer becomes uneven. Due to the skin effect, the skin depth decreases according to the square root of the frequency, and the $Z_{T}$ value decreases. In zone 3 (yellow) near $1 \mathrm{MHz}$, the transfer impedance value is determined by the scattering impedance $Z_{d}$, the small hole inductance $j \omega L h$, the braided inductance $j \omega \mathrm{Lb}$, and the additional wave attenuation, resulting in an obvious inflection point. As the frequency increases further, the magnetic field leakage caused by the diamond-shaped holes in the braided layer increases, and the inductance component of the small holes increases. The weaving of the braided bundles that intersect each other in the braid layer will cause the cutting of magnetic flux, which will also generate induced electromotive force, forming braided inductance, and increase the transfer impedance value. In the case of high frequency, the magnetic field between the inner and outer layers of the woven mesh will cause eddy current effects and additional attenuation. In area 4 (red), it is greater than $2 \mathrm{MHz}$, which is mainly determined by the small hole inductance and braided inductance. As the frequency increases, the transfer impedance value continues to increase $[14,15]$.

\section{Double-Layer Shielding Optimization Model}

According to the above analysis of the composition of the $Z_{T}$ curve, $Z_{T}$ is mainly determined by the DC resistance when zone 1 (gray) is less than $150 \mathrm{kHz}$. At present, high-voltage power cables on electric vehicles usually adopt double-layer shielding. In addition to the inner tinned copper wire woven mesh, the outer layer is also wrapped with a layer of aluminum-plastic composite tape (aluminum foil), so the tested power cables also need to consider the influence of the DC resistance of the aluminum foil on the transfer impedance value at low frequencies.

In addition, it can be seen from Figure 6 that because the double-layer shielded cable [16] adds a layer of aluminum foil to the outside of the shielding layer, compared with the singlelayer shielding, the diamond-shaped holes on the inside are covered by aluminum foil, which can effectively prevent the magnetic field from passing through small hole leaks, and the small hole inductance effect is greatly reduced and can be ignored. Therefore, it will affect the small hole inductance of the high-frequency part of area 4 (red) in Figure 5, and the transfer impedance value will theoretically decrease.

For the additional DC resistance value of aluminum foil, the aluminum foil layer model can be established by Q3D software for numerical analysis and calculation to extract the resistance value, as Figure 7 shows. Assuming that the aluminum foil model is ideal with a uniform thickness of $0.1 \mathrm{~mm}$, any section can be selected for calculation. In order to reduce the calculation amount, the length is set to $100 \mathrm{~mm}$, and the DC resistance of the aluminum foil in the cable under test is calculated. It is $0.004 \Omega / \mathrm{m}$.

Demoulin proposed an analytical model of formula (12), taking into account the effects of additional volatility.

The additional wave effect is the eddy current effect caused by the magnetic field between the braided bundles of the inner and outer layers of the woven net at high frequencies, which will generate additional attenuation and lead to a decrease in the transfer impedance value in the high-frequency range. This component can be described by the eddy current caused by the tangential electric field on the shielding layer and is proportional to $\sqrt{\omega}$. 


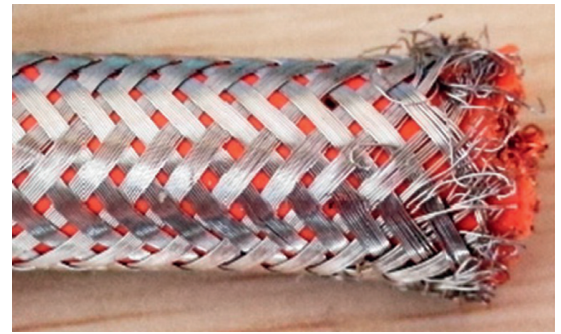

(a)

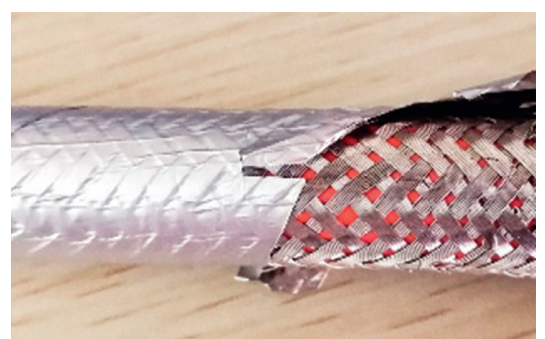

(b)

Figure 6: Single-layer shielded cable (a) and double-layer shielded cable (b).

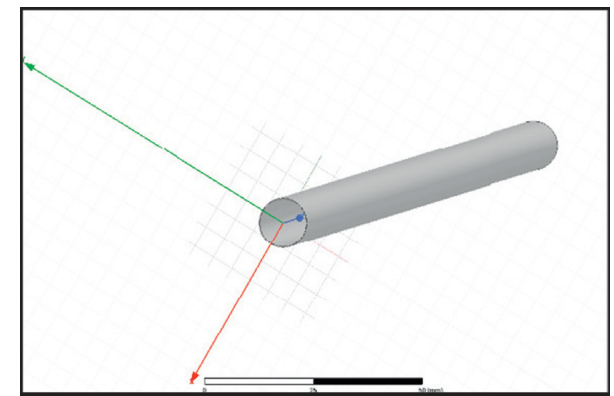

FIgUre 7: Aluminum foil Q3D calculation model.

$$
Z_{T \_ \text {Demoulin }}=Z_{d}+j \omega\left(L_{h 2}-L_{b 1}\right)+k \sqrt{\omega} e^{+j(\pi / 4)},
$$

where

$$
\begin{aligned}
Z_{d} & =R_{0} \frac{(1+j) d / \delta}{\sinh [(1+j) d / \delta]}, \\
R_{0} & =\frac{4}{\pi d^{2} N C \sigma \cos \alpha}, \\
\delta & =\frac{1}{\sqrt{\pi f \mu \sigma}}, \\
L_{h 2} & =\frac{2 \mu C}{\pi \cos \alpha}\left[\frac{b}{\pi D_{M}}\right]^{2} \exp ^{[(-\pi d / b)-2 \alpha]}, \\
L_{b 1} & =\frac{\mu h}{4 \pi D_{M}}\left(1-\tan ^{2} \alpha\right), \\
k & =-\frac{1.16}{N C d} \cdot \arctan \frac{N}{3} \cdot \sin \left(\frac{\pi}{2}-2 \alpha\right) \cdot \sqrt{\frac{\mu}{\sigma}} .
\end{aligned}
$$

Considering the impact of double-layer shielding, the equivalent circuit diagram of a double-layer shielded cable as shown in Figure 8 is obtained. Double-layer shielded power cables need to be considered in the analytical optimization model due to the influence of the DC resistance of the additional aluminum foil and the elimination of the small hole inductance on the transfer impedance.

In summary, the double-layer shielding optimization model is as follows:

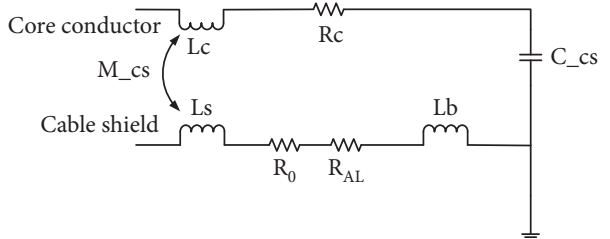

FIgURE 8: Equivalent circuit diagram of double-layer shielded cable.

$$
Z_{T \_D-D e m o u l i n}=Z_{d}^{\prime}-j \omega L_{b 1}+k \sqrt{\omega} e^{+j(\pi / 4)},
$$

where

$$
\begin{aligned}
Z_{d}^{\prime} & =R^{\prime} \frac{(1+j) d / \delta}{\sinh [(1+j) d / \delta]}, \\
R^{\prime} & =\frac{4}{\pi d^{2} N C \sigma \cos \alpha}+R_{A L}, \\
k & =-\frac{1.16}{N C d} \cdot \arctan \frac{N}{3} \cdot \sin \left(\frac{\pi}{2}-2 \alpha\right) \cdot \sqrt{\frac{\mu}{\sigma}}
\end{aligned}
$$

The single-layer shielding model and the double-layer optimization model were simulated and analyzed, as shown in Figure 9, considering increasing the DC resistance and eliminating the influence of the small hole inductance. It can be seen that the influence of the DC resistance is mainly in the low-frequency band and the influence of the inductance is in the high-frequency band. From the perspective of the overall optimization model, the transfer impedance of a double-layer shielded cable at high frequency is significantly lower than that of a single-layer shielded cable.

\section{Triaxial Method Test and Model Comparison Verification}

4.1. Triaxial Test. The triaxial method is a method in which the tested cable is placed in a coaxial nonferromagnetic good conductor tube for measurement, namely, the inner conductor of the cable core, the cable shielding layer, and the coaxial good conductor tube constituting a test device. The triaxial method can characterize the complex electromagnetic coupling mechanism [17] with directly measured 


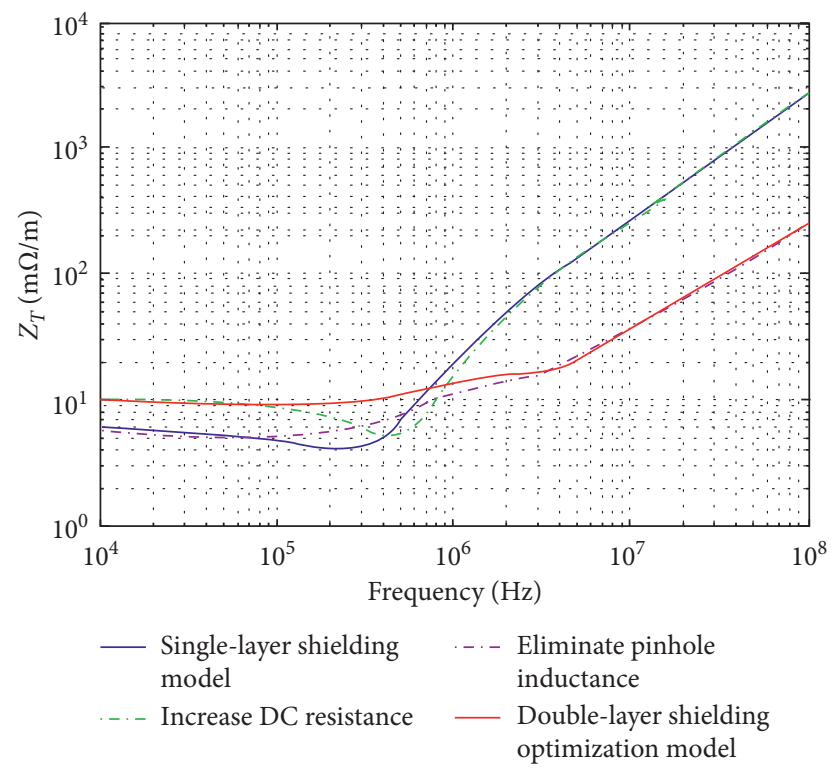

Figure 9: Comparison of single-layer shielding model and double-layer optimization model.

TABle 1: Comparison of three coaxial a, b, and c methods [18].

\begin{tabular}{|c|c|c|c|}
\hline $\begin{array}{l}\text { Testing } \\
\text { method }\end{array}$ & Test method a & Test method b & Test method c \\
\hline Advantage & Test cut higher stop frequency & $\begin{array}{l}\text { Measurement has more higher } \\
\text { dynamic range }\end{array}$ & $\begin{array}{c}\text { Suitable for measuring very low transfer impedance } \\
\text { values (below } 1 \mu \Omega / \mathrm{m} \text { m and lower) }\end{array}$ \\
\hline $\begin{array}{l}\text { Cutoff } \\
\text { frequency }\end{array}$ & $f_{\text {cut }} * l \approx 80 \mathrm{MHz} * \mathrm{~m}$ & $f_{\text {cut }} * l \approx 25 \mathrm{MHz} * \mathrm{~m}$ & $f_{\text {cut }} * l \approx 30 \mathrm{MHz} * \mathrm{~m}$ \\
\hline Disadvantages & $\begin{array}{l}\text { Low dynamic range of } \\
\text { measurement }\end{array}$ & Test cut lower frequency & $\begin{array}{l}\text { The effect of capacitive coupling is suppressed by the } \\
\text { short circuit in the primary and secondary circuits, and } \\
\text { the test is quite sensitive }\end{array}$ \\
\hline Features & $\begin{array}{l}\text { Matching resistance and } \\
\text { impedance mismatch } \\
\text { Need to connect to the } \\
\text { matching impedance network } \\
\text { Near-end core wire injection }\end{array}$ & $\begin{array}{l}\text { Only need to connect the } \\
\text { terminal matching resistor } \\
\text { Near-end core injection signal }\end{array}$ & $\begin{array}{l}\text { No matching resistor } \\
\text { No need to access matched impedance network inject } \\
\text { signal from remote test tube }\end{array}$ \\
\hline
\end{tabular}

circuit parameters (the electromagnetic field that affects the shielding effectiveness is replaced by surface current and surface charge equivalent), suitable for asymmetric cables and different size and structure complex connector testing, and the test results are repeatable.

Table 1 shows the comparison of triaxial methods $a, b$, and c. Considering the test stability, ease of operation, and commonality, this test adopts the triaxial B method; refer to the test standard: IEC62153-4-3-2013 [19]. Figure 10 shows the triaxial test layout of the power cable.

Calculation method of the triaxial $b$ method transfer impedance value:

$$
Z_{t}=\frac{R_{1}+Z_{0}}{2 \cdot L_{c}} \cdot 10^{-\left\{a_{\text {means }}-a_{\text {cal }} / 20\right\}}
$$

where $a_{\text {means }}=20 \log _{10}\left(S_{21}\right)$ represents the measured attenuation loss, $a_{\text {cal }}$ represents the composite loss measured during calibration, $Z_{0}$ represents the impedance of the signal generator and receiver, usually $50 \Omega$, and $L_{c}$ represents the coupling length of the tested cable and $R_{1}$ represents terminal impedance.

4.2. Comparison and Verification of Multiple Samples. Combined with the triaxial b method test schematic diagram (as shown in Figure 11), the flowchart of the power cable test was developed (as shown in Figure 12). As shown in Table 2, three double-layer shielded cables with different parameters were selected for testing. In the test, the coupling length of the three groups of samples is $0.5 \mathrm{~m}$. When the triaxial b method is used, the test cutoff frequency is $50 \mathrm{MHz}$ (the maximum measurable $50 \mathrm{MHz}$ ). As shown in Figure 13, the test value of the sample cable in the figure produces a resonance point at $50 \mathrm{MHz}$ and the trend of the transfer impedance curve changes. Comparing the simulation value of the double-layer shielding optimization model with the actual test value of the 


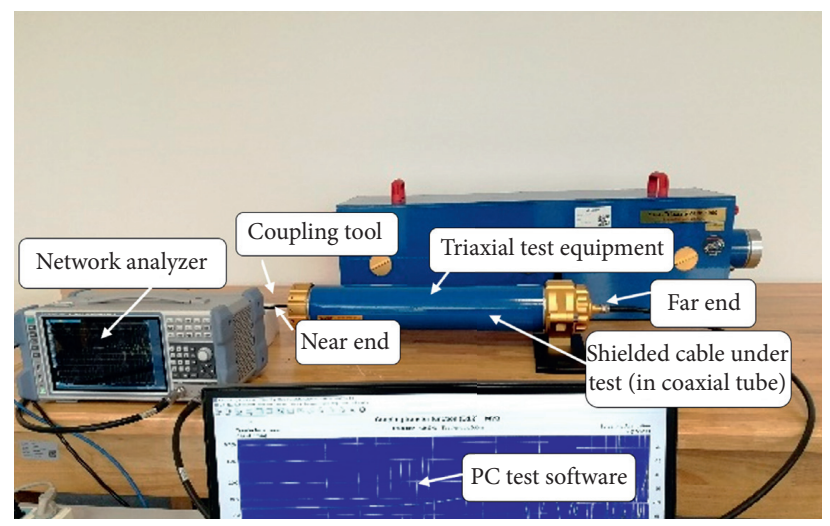

FIgURe 10: Physical diagram of power cable test layout.

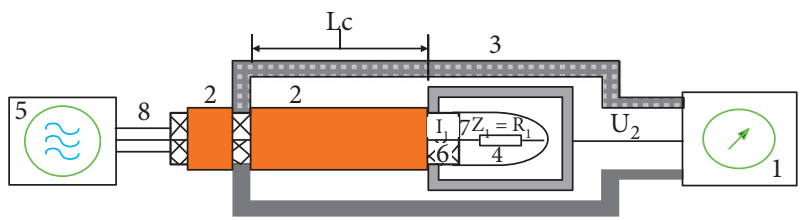

FIGURE 11: Schematic diagram of the test principle of the triaxial b method. (1) Network analyzer or receiver; (2) cable insulation sleeve; (3) test sleeve; (4) terminal impedance R1 length; (5) signal generator; (6) cable shield; (7) test core wire; (8) test connection line. $L_{c}$ : cable coupling.

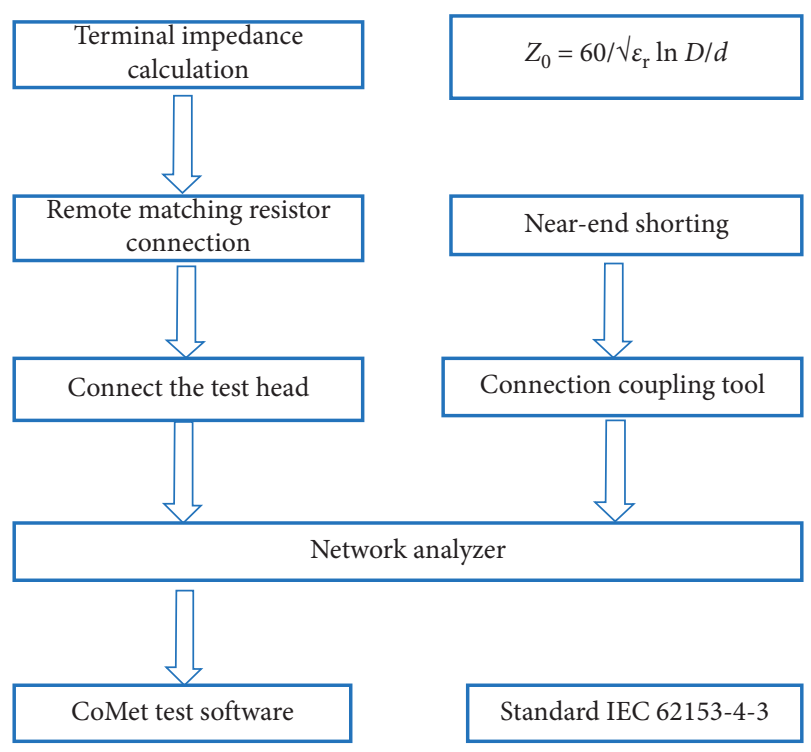

FIgURE 12: Power cable test flowchart.

TABLE 2: Sample cable parameters.

\begin{tabular}{lccc}
\hline & Sample 1 & Sample 2 & Sample 3 \\
\hline $\begin{array}{l}\text { Inner diameter of woven layer } D_{0} \\
(\mathrm{~mm})\end{array}$ & 10.3 & 11.58 & 10.02 \\
Braided wire diameter $d(\mathrm{~mm})$ & 0.15 & 0.15 & 0.15 \\
Number of braid strands $c$ & 8 & 10 & 10 \\
Number of wires per share $n$ & 24 & 24 & 24 \\
Weaving angle $\alpha$ & 35 & 38 & 38 \\
\hline
\end{tabular}

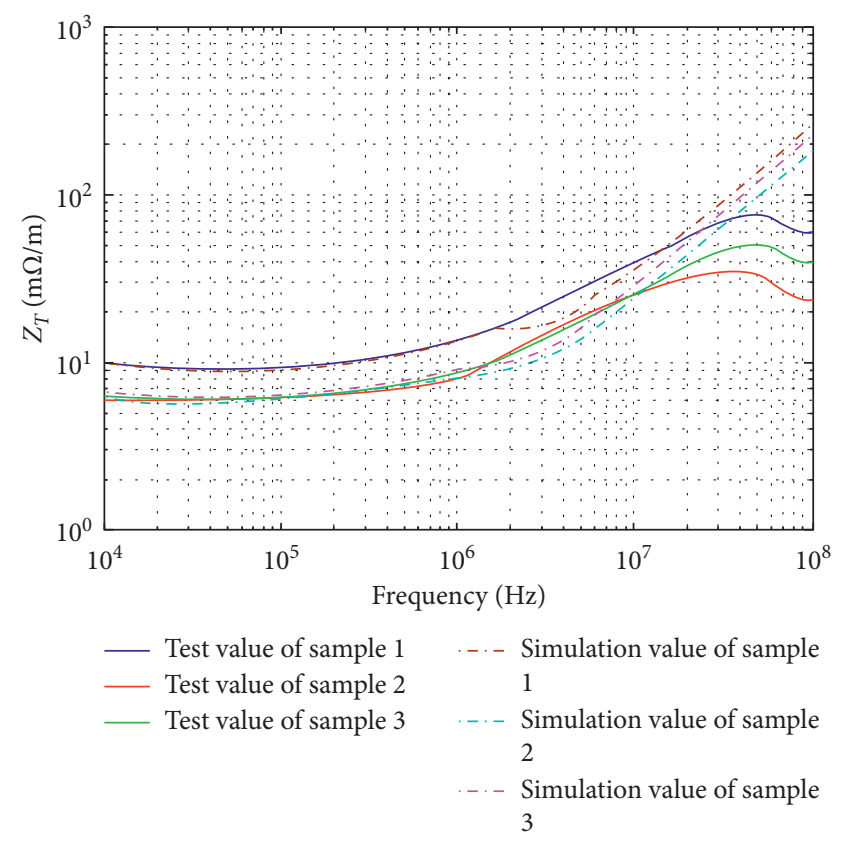

FIgURE 13: Comparison and analysis of simulated values and test values of samples 1,2 , and 3 .

sample cable, it can be seen that the simulation models of the three samples have a good fitting effect.

Table 3 shows the numerical comparison between the optimized model and the test value of three different samples at several common frequencies. As can be seen from the data in Table 3, the simulated calculated value of the optimized model at each frequency point is very close to the actual measured value after removing the keyhole inductance and considering adding the aluminum foil DC resistance. At the frequency of $150 \mathrm{kHz}$, the error rates of the three samples were $2.16 \%, 0.50 \%$, and $2.55 \%$, which were all lower than $3 \%$; at the frequency of $10 \mathrm{MHz}$, the error rates of sample 1 and sample 2 were $1.84 \%$ and $1.02 \%$, respectively, both less than $2 \%$, and the error rate of sample 3 is $9.01 \%$. At $1 \mathrm{MHz}$ and $2 \mathrm{MHz}$, the error rates of sample 1 were $7 \%$ and $8.86 \%$, respectively, which were lower than $9 \%$; the error rates of sample 2 and sample 3 were both lower than $12 \%$; at $20 \mathrm{MHz}$ 
TABLE 3: Comparative analysis of optimization model and test value.

\begin{tabular}{lccccccccc}
\hline $\begin{array}{l}\text { Frequency } \\
(\mathrm{kHz})\end{array}$ & $\begin{array}{c}\text { Sample 1 } \\
\text { test value } \\
(\mathrm{m} \Omega / \mathrm{m})\end{array}$ & $\begin{array}{c}\text { Sample 2 } \\
\text { test value } \\
(\mathrm{m} \Omega / \mathrm{m})\end{array}$ & $\begin{array}{c}\text { Sample 3 } \\
\text { test value } \\
(\mathrm{m} \Omega / \mathrm{m})\end{array}$ & $\begin{array}{c}\text { Sample 1 } \\
\text { optimization } \\
\text { model }(\mathrm{m} \Omega / \mathrm{m})\end{array}$ & $\begin{array}{c}\text { Sample 2 } \\
\text { optimization } \\
\text { model }(\mathrm{m} \Omega / \mathrm{m})\end{array}$ & $\begin{array}{c}\text { Sample 3 } \\
\text { optimization } \\
\text { model }(\mathrm{m} \Omega / \mathrm{m})\end{array}$ & $\begin{array}{c}\text { Sample 1 } \\
\text { error rate } \\
(\%)\end{array}$ & $\begin{array}{c}\text { Sample 2 } \\
\text { error rate } \\
(\%)\end{array}$ & $\begin{array}{c}\text { Sample 3 } \\
\text { error rate } \\
(\%)\end{array}$ \\
\hline 150 & 9.74 & 6.05 & 6.27 & 9.532 & 6.08 & 6.11 & 2.16 & 0.50 & 2.55 \\
1 & 12.72 & 8.06 & 8.27 & 13.61 & 8.72 & 9.13 & 7 & 8.19 & 10.40 \\
2 & 17.04 & 11.15 & 11.33 & 15.53 & 9.88 & 10.61 & 8.86 & 11.39 & 6.35 \\
10 & 37.52 & 24.52 & 25.86 & 36.83 & 24.27 & 28.19 & 1.84 & 1.02 & 9.01 \\
20 & 54.94 & 35.33 & 43.09 & 61.09 & 41.4 & 50.28 & 11.19 & 17.18 & 16.69 \\
30 & 68.37 & 48.07 & 57.93 & 78.14 & 57.56 & 69.05 & 14.29 & 19.74 & 19.20 \\
\hline
\end{tabular}

and $30 \mathrm{MHz}$, the error rates of the three samples were less than $20 \%$. In summary, the experimental data of the three samples and the calculation error rate of the optimization model in each frequency band were all less than $20 \%$, which verified the correctness of the optimization model and the universality of the optimization model.

\section{Conclusion}

(1) This paper analyzed the transfer impedance value representing the shielding effectiveness of the shielded cable, compared the difference between the single-layer shielded cable and the double-layer shielded cable, and clarified the influence of the double-layer shielded highvoltage connection cable commonly used in electric vehicles on the DC resistance and keyhole inductance of the shielded cable.

(2) Considering the influence of the shielding layer's DC resistance and small hole inductance, the optimization model $Z_{T \_D \text {-Desmoulins }}$ for the transfer impedance of the double-layer shielded cable was obtained, and the single-layer shielding model and the double-layer shielding model were simulated and analyzed. The influence of DC resistance in a lowfrequency band and inductance in a high-frequency band was determined.

(3) Three different types of double-shielded cables were selected for the triaxial test. The calculation error rates of the test data and the $Z_{T_{-} D \text {-Desmoulin }}$ optimization model in each frequency band were less than $20 \%$. At the frequency point of $10 \mathrm{MHz}$ that the enterprise focuses on, the error rates of the three double-layer shielded cables were all lower than $10 \%$, and two of them were $1.84 \%$ and $1.02 \%$, which almost coincided with the test data. The correctness and generality of the optimization model were verified, and it had good engineering application value.

\section{Data Availability}

The data used to support the findings of this study are included within the article.

\section{Conflicts of Interest}

The authors declare that they have no conflicts of interest.

\section{Acknowledgments}

This study was supported by the National Key R\&D Program of China (no. 2018YFB0106100), Key R\&D Program of Science and Technology Major Theme Project of Chongqing (no. cstc2018jszx-cyctzxX0005), and Direction Common Technology Program of Electric Vehicle Industry Technology Innovation Strategies Alliance (no. CA2019).

\section{References}

[1] G. M. Kunkel, "Transfer impedance testing of shielded cables, back shells, and connectors," Shielding of Electromagnetic Waves, pp. 69-71, 2020.

[2] O. Gassab, S. Bouguerra, L. Zhou, and W.-Y. Yin, "Efficient analytical model for the transfer impedance and admittance of noncoaxial/Twinax braided-shielded cables," IEEE Transactions on Electromagnetic Compatibility, no. 99, pp. 1-12, 2020.

[3] E. Vance, "Shielding effectiveness of braided-wire shields," IEEE Transactions on Electromagnetic Compatibility, vol. 17, no. 2, pp. 71-77, 1975.

[4] M. Tyni, "The transfer impedance of coaxial cables with braided conductors," in Proceedings of the EMC Symposium, Wroclaw, Poland, 1976.

[5] B. Demoulin and P. Degauque, "Shielding effectiveness of braids with high optical coverage," in Proceedings of the International Symposium on EMC, Zurich, Switzerland, 1981.

[6] K. Marconi, C. L. Andrade, V. D. Silva et al., "Evaluation of surface transfer impedance of coaxial cables," IEEE Latin America Transactions, vol. 18, pp. 598-603, 2020.

[7] W. Xiaoling, L. Chao, D. Hao et al., "An improved model for the transfer impedance calculations of braided coaxial cables," in Proceedings of the 7th International Power Electronics and Motion Control Conference (IPEMC 2012), Harbin, China, June 2012.

[8] A. Mushtaq and S. Frei, "Alternate methods for transfer impedance measurements of shielded HV-cables and HVcable-connector systems for EV and HEV," International Journal of RF and Microwave Computer-Aided Engineering, vol. 26, no. 4, pp. 359-366, 2016.

[9] K. Marconi and Andrade, "Evaluation of surface transfer impedance of coaxial cables," IEEE Latin America Transactions, vol. 18, no. 3, pp. 598-603, 2020.

[10] H. Schippers and J. Verpoorte, "Uncertainties in transfer impedance calculations," in Proceedings of the 2016 ESA Workshop on Aerospace EMC (Aerospace EMC), Valencia, Spain, May 2016.

[11] J. L. Rotgerink, J. Verpoorte, and H. Schippers, "Uncertainties in coaxial cable transfer impedance," IEEE Electromagnetic Compatibility Magazine, vol. 7, no. 3, pp. 83-93, 2018. 
[12] S. Bauer, C. Turk, W. Renhart et al., "Finite element analysis of cable shields to investigate the behavior of the transfer impedance with respect to fast transients," in Proceedings of the 2019 IEEE 23rd Workshop on Signal and Power Integrity (SPI), Chambery, France, June 2019.

[13] J. Verpoorte, H. Schippers, and J. H. G. J. Lansink Rotgerink, "Advanced Models for the Transfer Impedance of Metal Braids in Cable harnesses," in Proceedings of the 2018 IEEE International Symposium on Electromagnetic Compatibility and 2018 IEEE Asia-Pacific Symposium on Electromagnetic Compatibility (EMC/APEMC), Suntec City, Singapore, May 2018.

[14] S. Weber, S. Guttowski, E. Hoene et al., "EMI coupling from automotive traction systems," in Proceedings of the 2003 IEEE International Symposium on Electromagnetic Compatibility, Istanbul, Turkey, May 2003.

[15] S. Frei, A. Mushtaq, K. Hermes et al., "Current distribution in shielded cable-connector systems for power transmission in electric vehicles," in Proceedings of the IEEE International Symposium on Electromagnetic Compatibility and 2018 IEEE Asia-Pacific Symposium on Electromagnetic Compatibility (EMC/APEMC), Suntec City, Singapore, 2018.

[16] N. Mora, F. Rachidi, P. Pelissou, and A. Junge, “An improved formula for the transfer impedance of two-layer braided cable shields," IEEE Transactions on Electromagnetic Compatibility, vol. 57, no. 3, pp. 607-610, 2015.

[17] P. Xiao, P. A. Du, and B. Zhang, "An analytical method for radiated electromagnetic and shielding effectiveness of braided coaxial cable," IEEE Transactions on Electromagnetic Compatibility, vol. 61, no. 1, pp. 1-7, 2018.

[18] H. Kim and T. Jang, "Comparison of measurement results on the transfer impedance of a coaxial cable," in Proceedings of the 2017 Asia- Pacific International Symposium on Electromagnetic Compatibility (APEMC), Seoul, Republic of Korea, 2017.

[19] IEC 62153-4-3, 2.0 2013-10. Metallic communication cable test methods-part 4-3: electromagnetic compatibility (EMC)surface transfer impedance-triaxial method. 